\title{
Morbidity profile of Beedi workers in the Urban Field Practice Area of a Medical College in Tumakuru.
}

\author{
Chandana Krishna ${ }^{1}$, Uday Raghu ${ }^{2}$, Aneesh A Mathew ${ }^{2}$, Kiran Kumar', Praneeth Kumar²
}

\author{
${ }^{1}$ Assistant Professor, ${ }^{2}$ Interns. Department of Community Medicine, \\ Sri Siddhartha Medical College \& Research Centre, Tumakuru, Karnataka, India.
}

DOI -10.46319/RJMAHS.2018.v01i01.004

\begin{abstract}
Introduction: Beedi rolling is one of the most common and popular job to meet daily expenses, especially amongst women of India, in spite of it being a hazardous profession. According to government estimates quoted by International Labour Organization, there are close to 5 million workers involved in rolling of beedis in India. A Beedi worker in the process of rolling may inhale tobacco dust and other harmful components. Objectives: 1 . To describe the socio-demographic profile of study subjects. 2 . To assess the work characteristics of study subjects. 3 . To assess the morbidity profile of study subjects. Materials and Methods: This cross-sectional study was conducted in the urban field practice area of a Medical College, from June 2017 to December 2017. All the beedi workers (both gender) currently working from at least 6 months residing in above defined area were included in the study. A pretested semi-structured questionnaire was administered to the study subjects to collect information regarding socio demographic profile, work pattern and morbidity pattern. Results: The age of study subjects was $40.6 \pm 12.29 y r s$. Musculoskeletal symptoms $(41.66 \%)$ were the most common complaints followed by neurological ( $40 \%$ ), eye ( $21.66 \%$ ) and skin $(20.00 \%)$ symptoms. Conclusion: The most common morbidity was musculoskeletal followed by neurological, eye and skin symptoms.
\end{abstract}

Keywords: occupational health hazards, beedi workers, morbidity

\section{Introduction}

Health is an integral part of socio-economic development of any country. Health of a worker is dependent on type of work \& working environment. Occupational health hazards have an upward trend among large number of workers employed in unorganised and informal industry. Beedi industry is a vital agro-industry in Indian National Economy, prevalent in economically backward households as the industry was outsourced long back. Beedi rolling is one of the most common and popular job to reach daily expenses, especially amongst women of India, in spite of it being a hazardous profession. ${ }^{[1]}$

"Bidis" or "beedis" are slim, hand-rolled, unfiltered cigarettes. According to government estimates quoted by International Labour Organization, there are close to 5 million workers involved in rolling of beedis in India. ${ }^{[2]}$ Karnataka alone has more than 4 lakh workers in the beedi industry spread over the districts of Dakshina
Kannada, Udupi, Davanagere, Haveri, Mysore, Tumakuru, Dharwad, Bangalore (rural and urban). ${ }^{[3]}$ These individuals work in small industries or at household based enterprises in an environment laden with tobacco dust, of which $90 \%$ are home based women workers. A single woman on an average rolls 500-1000 Beedi's per day, using an average of 500 grams of tobacco flake. ${ }^{[4]}$ Beedi industry provides potential employment opportunity to a large number of people. It is estimated that around one million workers mostly woman and children are employed in Beedi making. ${ }^{[5]}$ Most of the Beedi making is carried out by the contractual, home-based, daily basis system. A Beedi worker in the process of rolling may inhale tobacco dust and other harmful components. Women spend hours,

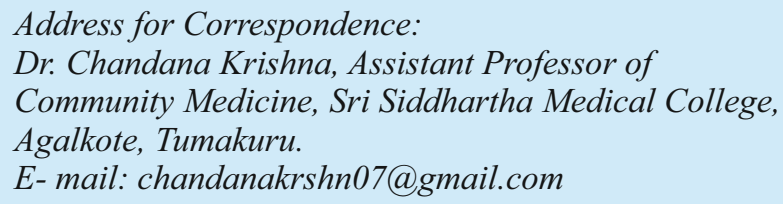


sitting rolling Beedis, surrounded by this harmful tobacco dust. ${ }^{[6]}$

Most of them live in one small room where they do the Beedi rolling along with cooking, sleeping and other daily activities. In view of the high content of nicotine and other harmful chemicals in Beedi tobacco (compared with cigarette tobacco), these workers are at extreme risk of developing systemic illness. Diseases like tuberculosis, asthma, allergy, backache, body ache, abdominal pain, gastritis, haemorrhoids etc. are the common hazards among beedi workers.

Hence the study was carried out to understand the socio demographic profile, work characteristics and morbidity profile of Beedi rollers residing in an urban slum, in the field practice area of a medical college.

\section{Materials and methods}

This cross-sectional study was conducted in the urban field practice area of a Medical College, between June 2017 to December 2017. After taking clearance from Institutional Ethical committee, all the 786 households in the urban field practice area were visited. Study subjects were selected by Universal sampling i.e, complete enumeration. All the beedi workers of both gender currently working from at least 6 months residing in above defined area were included in the study. 120 Beedi workers were present during survey and gave consent to the present study. A pretested semistructured interview schedule was administered to the study subjects by the investigators to collect information regarding socio demographic profile, work pattern and morbidity pattern. Confidentiality was ensured throughout the study.

Statistical Tests: The data was entered onto a Microsoft Excel 2007 spreadsheet and analysed using Epi info software version 7. Descriptive Statistics was applied for analysis.

\section{Results}

\section{Socio-demographic profile of study subjects:}

In the present study, the mean age of study subjects was $40.6 \pm 12.29 y$ yrs. Among the study subjects, majority (96.67\%) were females and all of them were Muslim by religion. Most of them were married (95\%) and were from nuclear families $(66.67 \%)$. Majority were illiterates $(41.67 \%)$ and belonged to Upper lower socioeconomic status $(83.33 \%)$ according to Modified
Kuppuswamy classification. Majority were living in good housing conditions $(63.33 \%)$. (Table 1)

Table 1: Demographic Profile and Work

Characteristics of Beedi Workers $(\mathrm{N}=120)$

\begin{tabular}{llc}
\hline \multicolumn{1}{c}{ Characteristics } & Freq. (\%) \\
\hline \multirow{2}{*}{ Gender } & Female & $116(96.67)$ \\
Religion & Male & $4(3.33)$ \\
Marital status & Muslim & $120(100.00)$ \\
& Married & $114(95.00)$ \\
Type of family & Widow & $6(5.00)$ \\
& Joint family & $40(33.33)$ \\
& Nuclear & $80(66.67)$ \\
& Graduate & $2(1.67)$ \\
Education & High school & $16(13.33)$ \\
& Middle school & $20(16.67)$ \\
& Primary school & $32(26.67)$ \\
& Illiterate & $50(41.67)$ \\
Socio-economic status & Upper lower & $100(83.33)$ \\
& Lower middle & $2(1.67)$ \\
& Lower & $18(15.00)$ \\
Housing condition & Satisfactory & $76(63.33)$ \\
& Unsatisfactory & $44(36.67)$ \\
\hline
\end{tabular}

SD: Standard deviation

\section{Work Characteristics of study subjects:}

In the present study, the study subjects have been working for 10 [Interquartile range(IQR):6-20]years. Income from beedi rolling was Rs. 1000 [IQR:600012000]. The study subjects rolled around 750 [IQR: 500-900] beedis per day. Majority worked for 5 days a week $(50.00 \%)$ and 5 hours per day $(40.00 \%)$

Table 2: Work Characteristics of Beedi Workers $(\mathrm{N}=120)$

\begin{tabular}{lcc}
\hline Work Characteristics & Freq. (\%) \\
\hline Working days/ week & 3 & $10(8.33)$ \\
& 4 & $12(10.00)$ \\
& 5 & $60(50.00)$ \\
& 6 & $34(28.33)$ \\
& 7 & $4(3.33)$ \\
Working hours/ day & 3 & $12(10.00)$ \\
& 4 & $22(18.33)$ \\
& 5 & $48(40.00)$ \\
6 & $32(26.67)$ \\
& 7 & $6(5.00)$ \\
\hline
\end{tabular}




\section{Morbidity pattern among study subjects:}

Among the study subjects, $16.67 \%$ were hypertensives, $8.33 \%$ were diabetics and $1.67 \%$ were hypothyroid.
Musculoskeletal symptoms (41.66\%) were the most common complaints followed by neurological $(40 \%)$, eye $(21.66 \%)$ and skin $(20.00 \%)$ symptoms.

Table 3: Morbidity pattern of Beedi Workers $(\mathrm{N}=120)$

\begin{tabular}{|c|c|c|}
\hline Morbidity pattern & & Freq. $(\%)^{*}$ \\
\hline \multirow{3}{*}{ Comorbidities } & Diabetes & $10(8.33)$ \\
\hline & Hypertension & $20(16.7)$ \\
\hline & Hypothyroidism & $2(1.67)$ \\
\hline \multirow{3}{*}{ Respiratory symptoms: 8 (6.66\%) } & Dyspnea & $4(3.33)$ \\
\hline & Wheezing & $4(3.33)$ \\
\hline & Excessive Sneezing & $2(1.67)$ \\
\hline \multirow{6}{*}{ Musculoskeletal symptoms: 50 (41.66\%) } & Myalgia & $34(28.33)$ \\
\hline & Small joints pain & $30(25.00)$ \\
\hline & Knee pain & $10(8.33)$ \\
\hline & Back pain & $9(7.50)$ \\
\hline & Shoulder pain & $7(5.83)$ \\
\hline & Neck pain & $2(1.67)$ \\
\hline \multirow{3}{*}{ Gastrointestinal symptoms: 21 (17.5\%) } & Abdominal pain & $6(5.00)$ \\
\hline & Gastritis & $18(15.00)$ \\
\hline & Headache & $42(35.29)$ \\
\hline \multirow[t]{2}{*}{ Neurological symptoms: 48 (40.00\%) } & Numbness & $4(3.33)$ \\
\hline & Weakness & $6(5.00)$ \\
\hline \multirow[t]{2}{*}{ Psychological symptoms: $12(10.00 \%)$} & Lack of sleep & $12(10.00)$ \\
\hline & Eye pain & $3(2.50)$ \\
\hline \multirow[t]{3}{*}{ Eye symptoms: $26(21.66 \%)$} & Watering & $6(5.00)$ \\
\hline & Diminished vision & $17(14.17)$ \\
\hline & Itching & $9(7.50)$ \\
\hline \multirow[t]{2}{*}{ Skin symptoms: $24(20.00 \%)$} & Hyperpigmentation & $15(12.50)$ \\
\hline & Nail pigmentation & $8(6.67)$ \\
\hline
\end{tabular}

*Multiple responses

\section{Discussion}

In the present study, age of study subjects was $40.6 \pm 12.29 y r s$, whereas study by Madhusudan et al \& Ghosh et al showed $40.8 \pm 11.3 \mathrm{yrs} \& 45.9 \pm 12.66 \mathrm{yrs}^{[7,8]}$. More than $90 \%$ of study subjects were females, which is supported by various other studies. All India Beedi, Cigar and Tobacco workers Federation estimated that women comprises $90-95 \%$ of total employment of beedi manufacturing. ${ }^{[9]}$

All the study subjects were Muslim by religion which was contrary to other studies by Madhusudan which showed Hindu as the common religion. ${ }^{[7]}$

Majority of study subjects were illiterates in the present study whereas the study by Madhusudan showed that majority were educated till Primary school. Majority of our study subjects belonged to Upper-lower socioeconomic status whereas study by Madhusudan et al showed that majority belonged to middle class. ${ }^{[7]}$

In the present study the subjects were working since 10 years which was contrary to other studies by Rajashekar et al \& Sudarshan et al, which showed study subjects working for $>15$ years. ${ }^{[2,10]}$ The average income from beedi rolling was found to be Rs.1000/- which was similar to study by Rajashekar et al and Madhusudan et al. $^{[7]}$

In the present study, musculoskeletal symptoms were the common health problems followed by neurological, 
eye and skin symptoms. Study by Rajashekar et al showed that health problems faced by beedi workers were backache, eye problems, headache \& asthma. ${ }^{[2]}$ Vinod Sen, reported that $67 \%$ beedi workers experienced pain in limbs and shoulder, $62.8 \%$ headache, $51.43 \%$ back pain, $44.3 \%$ continuous cold and allergy, $20 \%$ eye problems, $17.57 \%$ GI disturbances and $11.13 \%$ asthma. ${ }^{[11]}$

Myalgia (28.3\%) was the most common musculoskeletal problem among study subjects followed by small joints pain (25\%), knee pain (8.33\%), back pain (7.5\%), shoulder pain (5.83\%) and neck pain (1.67\%). Study by Ghosh et al showed low back pain $(79.7 \%)$ as the common musculoskeletal problem followed by shoulder pain, neck pain, knee pain etc. ${ }^{[8]}$

In the present study, most common illness was hypertension (16.7\%) followed by Diabetes $(8.33 \%)$ and hypothyroidism (1.67\%). In a study by Madhusudan et al, hypertension was common illness (60.5\%) followed by Asthma, diabetes, Ischemic heart diseases. ${ }^{[7]}$

\section{Conclusion}

From the present study we conclude that most of the Beedi rollers involved in this occupation were females, from poor socio economic status and illiterates. Beedi rolling plays an important role in the household economy both in terms of income and employment. The most common morbidity being musculoskeletal followed by neurological, eye and skin symptoms.

\section{Recommendations}

Creation of awareness among beedi workers regarding proper working posture with arm and back rest; and taking breaks at regular intervals of 1-1.5 hours; good ventilation in the working area, hand hygiene reduces the occurrence of occupational morbidities.

\section{Financial support and sponsorship: Nil}

\section{Conflicts of interest: $\mathrm{Nil}$}

\section{References}

1. GandhariBasu, Deblina Sarkar, Ranabir Pal, Suman Kumar Roy, Raju Dasgupta. Morbidity Audit of Women Beedi Workers in an Urban Fringe of West Bengal, India. Journal of Clinical and Diagnostic Research. 2018 Mar, Vol-12(3): LC05-LC09.
2. Rajasekhar D, Sreedhar G. Changing face of beedi industry. A Study in Dakshina Kannada. Economic and Political Weekly 2002; XXXVI: 4023-8.

3. Business Line. Internet edition. ILO Workshop to address problems of beedi sector. Financial Daily,2001, February 23rd; The Hindu group of publications.(cited 2009 October 8th).Available from: http://www. hinduonnet.com/businessline/2001/02/23/stories/03231 5ps.html

4. K.P. Joshi, M. Robins, Parashramlu, Venu and K.M. Mallikarjunaih. An epidemiological study of occupational health hazards among Beedi workers of Amarchinta, Andhra Pradesh. Acad. Indus. Res. February 2013 Vol. 1(9).

5. Nakkeeran, Senthil K, and Pugalendhi, Bharathi S: A study on occupational health hazards among women Beedi rollers in Tamilnadu, India. International Journal of current research. December 2010; Vol.11 (1):117-12.

6. Sabale RV, Kowli SS, Chowdhary PH. Working condition and health hazards in Beedi rollers residing in the urban slums of Mumbai. Indian Journal of Occupational and Environmental Medicine. 2012; 16(2): 72-74.

7. Madhusudan M, Patil D, Jayaram S. Occupational Health Profile of Beedi Workers in Coastal Karnataka. Natl J Community Med 2014; 5(2):157-160.

8. Ghosh P C, Iqbal R, Bairwa B L, Roy C, Subhash C. Occupational health profile of the beedi workers and ergonomic intervention. Indoshnews, Central Labour Institute 2005;10: 8-13.

9. Chauhan Y. History and struggles of bidi workers in India. New Delhi: All India Trade Union Congress. 2001.

10. Sudarshan R and Kaur R. The tobacco industry and women's employment: old concerns and new imperatives. Indian J Labour Econ 1999; 675-85.

11. Sen V. Effects of working condition on Health of Beedi Workers: A Study of Sagar District of Madhya Pradesh. In: Arnab Ghosh, editor. Environment, Drinking water and Public Health: Problems and future goals. Daya publishing house, Delhi2007: pp 132-49. 